\title{
The Cognitive Mechanism of Humor-Based on Conceptual Blending Theory and Relevance Theory
}

\author{
KANG Xinyu, GAO Wencheng \\ University of Shanghai for Science and Technology, Shanghai, China
}

\begin{abstract}
Humor, as a form of interesting interaction, often appears in our daily life. The purpose of this paper is to explore the cognitive mechanism of humor. It is found that humor is dependent on people's relevance and inference in their minds, and also on the conceptual blending with its emergent structure. The authors hold that these two theories are supplementary to each other; the combination has even more powerful interpretation about the workings of humor generation.
\end{abstract}

Keywords: humor, conceptual blending theory, relevance theory

\section{Introduction}

Lin Yutang translated the Latin "humour" into Youmo in Chinese, who is famous for his translation and linguistic studies in China. Later, humor was applied to many comedies and was favoured by many Chinese people. People in foreign countries are often regarded as having more spirits of humor and entertainment. The sense of humor cannot only be found in their literary works but also in their daily life and social customs. However, in the old feudal society of China, Chinese people are expected to stick to the principles of mutual respect, modesty, and being prudent of wording in communication. Humor is now widely accepted and appreciated throughout the world. In addition, humor has cultural characteristics. To put the same humor in different cultures, its interpretation and feedback are apparently varied.

Actually, humor is not one-side activity but a process of interaction with cognition. The interpretation of this process is based on two theories: the relevance theory and the conceptual blending theory. Besides the theoretical basis, the explanation of the related language model is necessary. The process of generating and interpreting humor is closely connected with language expression, common knowledge, contextual situation, and background information. Thus, people try to learn to use humor appropriately and try to understand them correctly. However, humor sometimes is hard to appreciate according to the speaker's language, thinking mode, and cultural differences. What are the inner workings of humor comprehension? Different scholars have explored the mechanism of humor from different perspectives.

KANG Xinyu, master, College of Foreign Languages, University of Shanghai for Science and Technology, Shanghai, China. GAO Wencheng, doctor, professor, College of Foreign Languages, University of Shanghai for Science and Technology, Shanghai, China. 


\section{Literature Review}

At present, there are four popular perspectives in the field of humor research, namely, cognitive linguistics, discourse, semantics, and pragmatics.

\section{From the Perspective of Cognitive Linguistics}

There are a series of theories which provide abundant theoretical basis and innovative research perspectives, from the earlier semantic script theory (Raskin, 1985) to the generation theory of verbal humor, and then to the conceptual blending theory (Fauconnier \& Turner, 1998). Coulson (2000) first applied a cognitive model of conceptual blending theory to humor analysis. Moreover, Coulson also investigates both event-related potential and reading time, proving that the hearer transmits the frame of humor to comprehend and appreciate the humor simultaneously. For conceptual structure, it is more imperative to comprehend the emergent structure. Wang and Lin (2003) had shown that the construction of humor relies on emergent structures; $\mathrm{Xu}$ (2003) explained that the cognitive process of humor generation is the combination of the relevance theory (Sperber \& Wilson, 1995) and conceptual blending theory.

In recent years, with the familiarity of humor in people's communication, the diversification of humor generating mechanism begins to occur. The phenomenon of inconformity exists in humor production. Liu (2005) had examined three aspects: cognitive frame, conceptual blending, and conceptual contrast. He argues that the laughing reason is a discrepancy between the new and the one that has existed in people's mind.

According to Jiang (2007), a complementary research about conceptual blending theory and violation-normality theory has been put forward. Jiang states that the explanatory power of conceptual blending theory has some limitations in explaining the conditions of humor generation. Using Veatch's (1998) violation-normality theory, a new interpretation model has been constructed. Another creative aspect is to analyze the process of interpretation in the incongruity theory by using conceptual metaphor and Chinese recessive grade, aiming at exploring the cognitive mechanism (Zhao, 2008). Although some limitations can be found, Wei (2009) still deeply investigated the cognitive mechanism of humor from multidimensional aspects and constructs a new cognitive model on its foundation. In addition, Xiang (2010) suggested that the cognitive mechanism should be perceived as the most significant issue in humor research and cognitive science.

\section{From the Perspective of Discourse}

Fan (2005) thought that the underlying reasons of humor generation are the three register features including field, tenor, and mode.

\section{From the Perspective of Semantics}

Raskin (1985) thought that the purpose of semantic script theory of humor is to use script to express the unmarked cognitive construction. As the significant and basic theory, the semantic script theory of humor has an important influence in the field of semantics research. According to his argument, the generation of humor is due to the opposition of two scripts and their triggers. However, Attardo (1994) stated that the generation of humor is prompted by six elements which further develop the humor theories.

In addition, ambiguity is viewed as one of the factors which express the humor through the way of homophone, polysemy, or the obscure sentences (Shi, 2000). Yang (2003) focused on puns, which can be 
presented by two kinds of different explanations of humor by using polysemy between the phones and lexis. Another factor is alias, which appears in the riddle written on the lanterns in ancient China. Until the 19th century, it began to be studied as a way of rhetorical devices. According to Yang (2003), humor can also be produced in terms of reader's imagination and association during the process by which the lexical grammar and the rhetorical devices provide a new meaning on the basis of the conventional word.

\section{From the Perspective of Pragmatics}

In our daily life, humor is usually produced by violating cooperative principles or maxims according to the relevance theory and conversational implicature. Wang (2001) analyzed the relevance theory on the basis of examples. He argues that humor can be regarded as a significant part in language interactions. Humor can help to achieve communication demands. In practice, humor acts as a special language, which should be connected with politeness and face principles from the perspectives of a speaker and a hearer, aiming at using it appropriately in communication in order to take face into account (Liu \& Xiong, 2003).

\section{Introduction to Conceptual Blending Theory and Relevance Theory}

The conceptual blending theory (Fauconnier, 1997; Fauconnier \& Turner, 1998, 2002) is proposed on the account of the mental space theory. According to Fauconnier, the conceptual blending theory is comprised of four related mental spaces including two input spaces from different conceptual domains; a generic space aims at generalizing the input issues; the last is the blended space. Some common structures and abstract information in the two input spaces have been connected and projected to the generic space, in which a set of information and selected parts will be projected to the blended space. In the last space, part of structures will be extracted so as to constitute the emergent structure. In this way, the four spaces can be linked up through projection chains.

Conceptual blending has three operational stages of composition, completion and elaboration (Fauconnier \& Tuner, 1998).

(a) Composition: Parts of elements through composition process form new relationship with each other. It is also a neo-category process.

(b) Completion: By virtue of framework knowledge, cognition, and cultural model, the composition structures will be projected to the blended space.

(c) Elaboration: The structures in the blended space can be elaborated, also called "running the blend". That is to say, the structures will operate according to their emergent logic.

In addition, Fauconnier states that these spaces are constructed during the process of communication and interaction. Some semantic elements, rules, strategies, and various relations can be brought in building these space domains.

Conceptual blending actually becomes the online meaning construction. It has strength explanatory power in language. However, in the course of humor interpretation, it has some limitations. Jiang (2007) gave a typical example for the purpose of proving that only the conceptual blending theory is insufficient.

Lawyer: When I was a child, my biggest dream was to be a pirate.

Client: You are so lucky, not everyone can realize their dream.

During this conversation, it is not hard to recognize that the conversation is about litigation. In the first input domain, the lawyer arose a cognitive domain about the pirate, while in the second input domain, the client 
arose lawyer's cognitive domain. Based on our conceptual blending theory, two input spaces need to be blended and produced the emergent structure. Meanwhile, these two input spaces are ambiguous and general, it is challenging for the readers to recognize how they can blend and make up in the blended space. Besides, what is the key point in the process of blending? How is the emergent structure produced?

Thus, some researchers, like Brandt (2005) had questioned the explanatory power of conceptual blending theory. Shu (2004) stated that the conceptual blending theory has its limitations. However, during the research, Sperber and Wilson (1995) showed that the relevance theory is developed from the cooperative principle, for the purpose of explaining the interaction meaning of a conversation. It is also applicable to the humor in a conversation, so the relevance theory can be a supplement for the conceptual blending theory.

According to Sperber and Wilson, every act of ostensive communication communicates a presumption of its own optimal relevance. People believe that when they handle the information, they always try to balance the cost that they have spent and the result that they have obtained. That is, they always find a kind of context in which they can spend minimum efforts but obtain maximum contextual effects. Instead, in humorous language, the speakers always choose the implied way to express their intentions so that the relevance is not stronger than in the assumed conversations. Hence, the interpreters need to spend more efforts to discover the relevance of utterances. These efforts will be returned in the way of contextual effects, presented as a sense of joy in the humorous language. That is why people love to appreciate humor even though they are difficult to understand.

A: Where's my cola?

B: Where are the snows of yesterday?

The conversation seems to have no relationship with this environment. But if we change B into another sentence like "The children were in your room this morning", the meaning is presented obviously.

The basic relevance principle is that in any given context, the sentences are always related to each other. In a special situation, people want to transmit a sort of information to somebody. The successful interactions need the related language to serve as their presupposition in which the contextual effect and the processing efforts are involved. The core of the relevance theory is the information manifestation. When a hearer tries to understand the communication, he has entered a process of ostensive-inferential communication. The most significant part of this process is to infer something special in the analysis of humor. But there are also limitations in the relevance theory. For example, the hearers need to interpret the speakers' intention by a successful inference, or they may produce embarrassed environment and misunderstanding. The relevance theory lacks a set of operational method. Therefore, the relevance theory and the conceptual blending theory can supplement for each other in explaining how humor is generated. .

\section{Cognitive Mechanism of Humor}

In order to better understand humor, a new model of cognitive mechanism of humor based on the two theories is trying to be constructed. In this model, the contextual situation and the inference process will be included. The specific process is as follows:

(a) The relevance relationship is the presupposition. In general, humorous languages are usually hidden behind the surface meaning. In other words, humor can be interpreted if the related things are found.

(b) Verbal humor languages are input in the first input space.

(c) Contextual situation and inference analysis are input in the second input space.

(d) Blending the two input spaces and then producing the emergent structure. 
(e) Understanding and appreciating the emergent structure.

Through this model, the pirate and the lawyer will be put in the first input space. "Pirate" is able to raise the conceptual domains, like victims, hijack, properties, and so on. "Lawyer" can remind people of clients, consignors, lawsuit fees, and so on. In the first input, the pirate corresponds to the lawyer; the victims correspond to the consignors; the properties correspond to the lawsuit fees. Through the contextual situation and inference, the relationships between the lawyer and client are divided into two levels: the protection and be safeguarded; the robbery and plunder. After blending the emergent structure is produced, which means the understanding process is finished.

Here is a humorous story as an example:

The country man was visiting the big city for the first time. Entering an office building, he saw a pudgy woman stepped into a small room. The door closed, lights flashed and after a while the door opened and a beautiful model stepped off the room.

Blinking in amazement, the country man said slowly, "I should bring my wife here!” (Wang \& Lin, 2003, p. 32-38)

From the surface level, we find no related clues with the last sentence. If we analyze the meaning in the contextual situation, it is not difficult to deduce that the country man hopes his wife is as beautiful as the model. In our real life, the miracle of a pudgy woman changing into a beautiful model is impossible. Thus, after blending all the related conceptions, the emergent structure will be generated. The country man regards the two women as the same person and then the humor is produced. The purpose of this humorous story is to express satirically that the country man is an idiot.

The following is another instance of humor:

An overweight patient asked a doctor to lose his weight in a healthy way. The doctor told him, "You should eat regularly for two days, and then skip a day. Repeat this process for two weeks; you can lose about six pounds."

After one month, the patient returned and said he had lost about twenty pounds. The doctor was surprised and asked if he had obeyed the instruction. He said, "I did well except I was going to drop dead for the third day."

In this instance, the key point is the "skip a day". According to the contextual situation, we can infer that to skip a day here means not to eat food in one day. However, the patient misunderstood the doctor's instruction. According to the conceptual blending theory, it is easy to infer the emergent structure rather than doing the drop for a day. This instance proves that, the conceptual blending theory can provide supplement for the relevance theory.

In Wang and Lin's (2003, p. 32-38) study, more examples are provided.

The girl and her boyfriend were riding in a car when her boyfriend asked her to put on the seatbelt. The girl smiled and was touched by her boyfriend's concern for her safety. Then her boyfriend added, "I don't want to get the tickets."

Here, the relevance relationship appears between the boyfriend's language, the contextual situation, and the girl's inference. The car belongs to the boyfriend and they should obey the transportation rules. So, the worry of the girl's boyfriend is totally related to the context. However, when we put the added sentence into the input spaces, we find that the emergent structure of the conceptual blending theory is inconsistent with the 
thought existing in her mind. Actually, the emergent structure aims to present her self-sentimentality in terms of humor.

This new model of cognitive mechanism of humor has effective explanatory power. The following example gives us a clear picture about how the conceptual blending is operated.

A man bought a bag of cigar in a store while he lit it still in the store. The clerk told him to put it out because smoking wasn't allowed in the store. "What do you mean?" the man said, "you sell the cigars but don't allow smoking." "We also sell bath towels," said the clerk.

The key point of this humor is in the last sentence: We also sell the bath towels. The reason why the man smoked in the store is that the place where the cigars are sold should be allowed to smoke. But the contradictory view of the clerk is that the store also sells bath towel. If we suppose what the man said is right, then that the people who buy the bath towels can take a shower in the store is also accepted. But actually, it is ridiculous. Thus, there exists a relevance relationship involved in what the man and the clerk said. When the man heard the clerk, he knew she was correct, but he needed to infer because she did not express her opposition directly. So, he concluded that there was no logical relationship in the event of smoking cigars and selling cigars. Through blending the context and humorous elements, the man obtained the emergent structure which implied that the clerk was opposite to his opinion indirectly.

\section{Conclusion}

As we all know, humor is a special and interesting interaction in communication. So far, the research of humor has been gradually conducted by many scholars from different perspectives. The conceptual blending theory and relevance theory have their own advantages and limitations, but they can supplement for each other in explaining humor. Only through the conceptual blending operation can the relevance theory achieve the intention of the interlocutors. In this new working model, besides the two input spaces, generic space and blended space, the emergent structure is the most significant part. The implied meaning and new conclusion can be deduced through this emergent structure, which is also the necessary condition for humor analysis. Contextual clues are also needed in the process of integration.

\section{References}

Attardo, S. (1994). The linguistic theory of humor. Berlin/New York: Mouton de Gruyter.

Brandt, P. A. (2005). Mental spaces and cognitive semantics: A critical comment. Journal of Pragmatics, 10(37), 1578-1594.

Coulson, S. (2000). Semantic leaps: Frame-shifting and conceptual blending in meaning construction. Cambridge: Cambridge University Press.

Fan, X. T. (2005). A functional linguistic analysis of humor (Master degree thesis, Jiangxi Normal University).

Fauconnier, G. (1997). Mappings in thought and language. Cambridge: Cambridge University Press.

Fauconnier, G., \& Turner, M. (1998). Conceptual integration network. Cognitive Science, 22(2), 133-187.

Fauconnier, G., \& Turner, M. (2002). The way we think. New York: Basic Books.

Jiang, B. Q. (2007). A cognitive study on the generation mechanism of verbal humor. Journal of Xi'an International Studies University, (4), 19-22.

Liu, N. S., \& Xiong, X. L. (2003). A brief analysis on face-saving function of verbal humor. Foreign Language Education, (6), $10-13$.

Liu, P. (2005). A literature review of linguistic studies on verbal humor. Journal of Xiangtan University, (5), 152-154.

Raskin, V. (1985). Semantic mechanisms of humor. Dordrecht: Reidel.

Shi, J. (2000). Ambiguity in English humor. Journal of PLA University of Foreign Languages, (3), 35-37.

Shu, D. F. (2004). Cognitive studies of language. Shanghai Foreign Language Education Press. 
Sperber, D., \& Wilson, D. (1995). Relevance: Communication and cognition. Oxford: Blackwell Publishers Ltd.

Veatch, T. (1998). A theory of humor. The International Journal of Humor Research, 11(2), 161-215.

Wang, W. B., \& Lin, B. (2003). English verbal humor: A cognitive pragmatic inquiry. Journal of Foreign Languages, (4), 32-38.

Wang, Y. (2001). A study of verbal humor from the perspective of relevance theory. Foreign Language Education, (1), 23-27.

Wei, W. C. (2009). Multidimensional research of verbal humor (Doctoral thesis, Zhejiang University).

Xiang, C. D. (2010). A study of the interaction between cognitive linguistics and humor research. Foreign Language Education, (1), 35-39.

Xu, L. X. (2003). The analysis of verbal humor. Kaifeng: Henan University Press.

Yang, J. (2003). Abstract research on the types of humor language and application (Master Degree thesis, Yanbian University).

Zhao, Q. (2008). An analysis of recessive scalar humor with metonymy as a tool. Journal of PLA University of Foreign Languages, (1), 15-21. 